\title{
Ridership Demand Analysis for Palestinian Intercity Public Transport
}

\author{
Khaled A. Al-Sahili and Abdelmajid H. Sadeq \\ An-Najah National University
}

\begin{abstract}
This article presents results of research to study the intercity bus ridership demand, assess existing services, and form a basis to predict future ridership in the Palestinian territories. This study is the first of its type in the area.

Intercity public transport between six governorates in the northern and central districts of the West Bank was examined. The relationship between public transportation demand and both operating and socioeconomic variables that influence demand was established. An on-board survey of intercity bus riders identified some of the variables that can potentially influence ridership demand. A simple linear regression equation of the ridership demand was developed using five independent variables: population of origin city, population of destination city, bus fare, percent of employees at origin city, and percent of higher education students at origin city. Ridership profiles and trip characteristics were also established.

The study results can be used to evaluate existing public transportation and forecast future intercity public transport demand. Decision-makers can use the results to improve intercity public transport services and attract more riders. Future research should be based on this simple model, include the impact of other modes on intercity de-
\end{abstract}


mand, include all governorates of the West Bank and Gaza Strip, and establish a comprehensive nationwide model.

\section{Introduction}

Public transportation plays an important role in fulfilling transport needs. Transportation planners around the world direct their research and studies toward the development of public transportation using different technologies. Research efforts focus on increasing the efficiency of the existing public transportation system using different strategies to achieve objectives. One strategy deals with the analysis and modeling of demand for travel.

Many factors-external and internal-affect public transport demand. External factors are associated with socioeconomic developments, which are not subject to control (e.g., income, car ownership, population, employment, other household characteristics). Internal factors are characteristics of the public transport system and are subject to policy decisions (e.g., public transport fares, trip length, travel time, service levels).

\section{Background}

Upon launching of the peace process between the Palestine Liberation Organization and Israel in 1993, the Palestinian National Authority (PNA) gradually resumed control over some parts of the West Bank and Gaza. During the last 35 years of occupation, the comprehensive intercity public transport system in the West Bank was partially destroyed. The role of municipalities and other transport authorities was limited in the area of transportation facilities improvements. After 1995, the PNA started several transportation development projects, including rehabilitation of road networks, transportation systems management for major cities in the West Bank and Gaza Strip, and downtown traffic management. However, there was no fund assigned to the development of the public transportation facilities at the time except by the private sector. The decision to postpone public transportation development during this period was based on several factors:

- Public transportation agencies are privately owned

- Traffic congestion on intercity roads is not a serious problem

- PNA focused on infrastructure rather than operation projects

- Most intercity roads still are not controlled by the PNA

- Some public transportation development projects need public awareness 


\section{Significance and Objective of the Study}

As a result of these factors, the public transportation services needed to determine future needs and demands of riders were not recognized nor studied. Therefore, there is a need to evaluate existing public transportation in the Palestinian territories to meet expected growth in automobiles on Palestinian roads, which is expected to cause more congestion and delays.

Ridership demand analysis and modeling for public transport had been studied extensively in many developed countries. However, this study is the first of its kind in the Palestinian territories. It was designed to understand some aspects of intercity bus travel behavior and establish a simple demand model.

This study is intended to develop a simplified model of the existing intercity public transportation and forecasting ridership. In turn, the model can be used to create a framework to assist policy-makers in the decision management process of public transportation (e.g., increasing transit ridership, as recommended by Wilbur Smith Associates [2000]). Bus company owners can also use the study results to improve their services and attract new customers.

\section{Intercity Public Transport}

Two types of intercity public transport are common in the West Bank: shared taxis and buses. For all study routes, both modes are available and riders can choose between either mode.

Shared taxi is considered a paratransit service. It is privately owned and operated. The standard intercity shared taxi seating capacity is seven passengers. Services may deviate from routes and/or fixed schedule, and may pick up and drop off passengers at other than regular stops. Shared taxi is normally faster and more expensive than bus service. The majority of passengers ride at the origin terminal and take off at the end point. Therefore, it is similar to an express service.

Intercity bus service is the public transportation mode that connects between cities. Intercity bus offers fixed-fare services weekdays on a fixed route and somewhat fixed schedule. Intercity bus service is currently provided by private companies, which operate at a profit, with little or no support from the government. Trip travel time is normally longer and trip fare is cheaper than shared taxis for the same origin-destination. 


\section{Study Area}

The area of study for this research was the northern and the central governorates of the West Bank. The core of the study was Nablus City, which connects the northern districts with the central and southern districts of the West Bank. In terms of population, Nablus City is the second largest city in the West Bank after Hebron. It is also considered the largest commercial center. Nablus City has the largest university in the West Bank (in terms of number of students), and it is centrally located among other cities in the West Bank. Figure 1 illustrates the location of the main cities/governorates in the West Bank.

\section{Figure 1. Map of the West Bank and Gaza Strip}

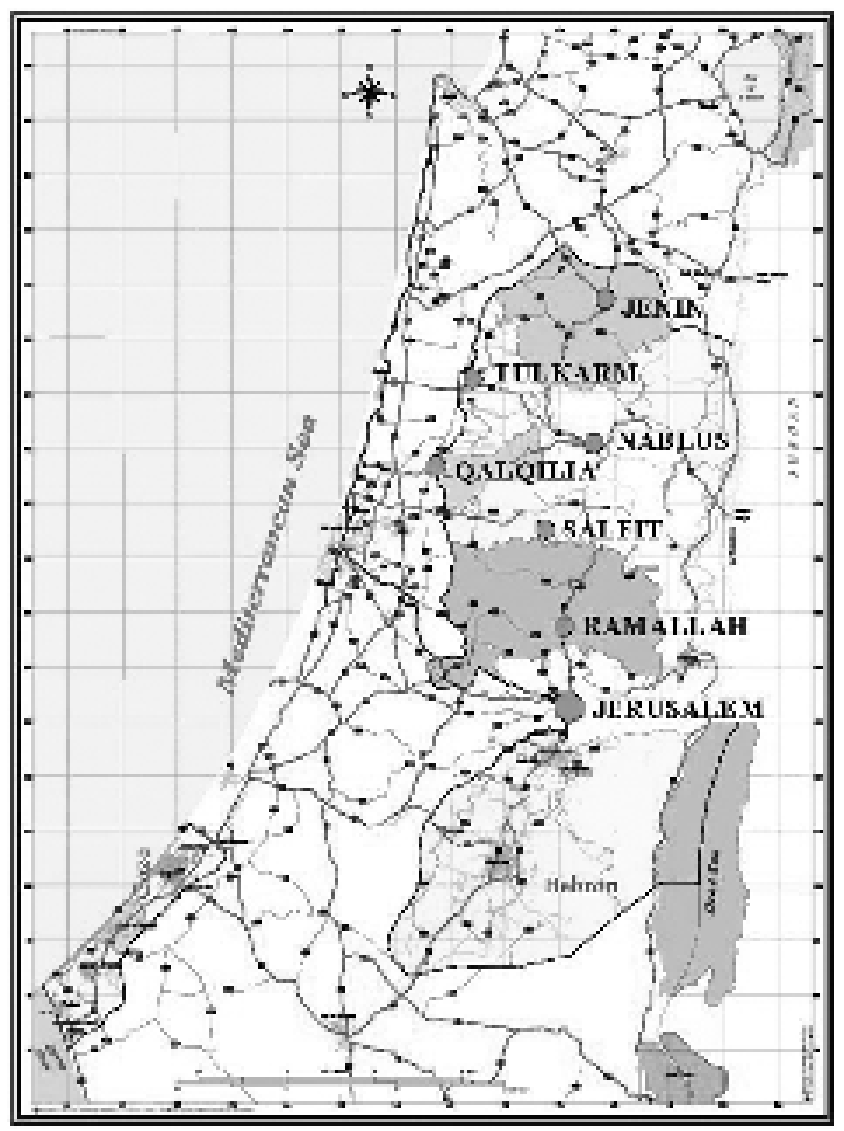




\section{Literature Review}

Historically, the analysis of factors affecting the demand for public transport goes back about 100 years. Many studies have been conducted in this field, addressing different points of view.

Bermello, Ajamil, and Partners (1997) discussed transit ridership demand in several statewide and regional studies in the United States and expressed the demand model as:

Ridership $=$ Constant $(\text { Population })^{\mathrm{a}}(\text { Service Frequency })^{\mathrm{b}}(\text { Distance })^{\mathrm{c}}(\text { Fare })^{\mathrm{d}} \ldots$

The study also investigated ridership demand for the Tri-Rail routes connecting the south Florida region. Tri-Rail ridership was a direct demand function of the service area demographics (population of the origin and destination stations, average population age, and income of the origin station) and route characteristics (average travel time, distance, and fare).

Al-Sahili and Taylor (1996) used the 1977 Michigan intercity bus ridership data to develop a demand model between city pairs and presented this mathematical relationship:

$$
\begin{gathered}
\mathrm{R}_{\mathrm{ij}}=(\text { Constant) } \\
\text { (Population for City i) })^{\mathrm{a}}(\text { Population for City j })^{\mathrm{b}} \\
\text { (Distance between two cities) }^{\mathrm{c}}
\end{gathered}
$$

Moussavi et al. (1996) developed models to predict future public transportation ridership demand in rural Nebraska. Existing and historical transit operation and socioeconomic and demographic data for counties and cities in Nebraska that had rural transportation services were used to develop a series of equations for predicting future ridership demand in rural areas with or without existing public transportation services.

The results of Moussavi's research were expected to enhance the capabilities of decision-makers at the Nebraska Department of Roads in setting priorities for meeting the public transportation needs in rural Nebraska. The general forms of equations developed in Moussavi's study were:

Annual passenger $=a_{1}$ VehMile + Constant Annual passenger $=a_{1}$ VehMile $-a_{2}$ AvgFare + Constant 
The first form was for areas that did not charge a fare while the second was for areas that did charge a fare, with $\mathrm{a}_{1}$ and $\mathrm{a}_{2}$ coefficients for annual vehicle miles (VehMile) and the annual average fare (AvgFare), respectively.

Most models were simple and analytical mathematical formulas based on the characteristics of surrounding communities and transit agencies. Most followed a loglinear format and few used a linear format. Factors affecting public transport demand were associated socioeconomic developments, which are not subject to control by the researchers. Internal factors, characteristics of the public transport system and subject to policy decision, were also used. The aggregate data on interdistrict travel by public transportation were used to calibrate a total demand model with influence factors.

\section{Methodology}

To be consistent with the general form of public transport simple demand models as depicted from the literature, statistical analysis and least square regression were used. In this research, the correlation and causation of independent and dependent variables were examined. The procedure used in this study involved examining various independent variables that can potentially influence demand. These variables were selected based on previous literature, knowledge of the area, and the survey of riders.

One of the key research steps was conducting a comprehensive on-board survey (sample size $=410)$ of riders on all intercity public transport study routes. The survey was designed to examine riders' profile and trip characteristics. It was used to identify some of the primary independent variables that could influence ridership demand.

Various relationships of a log-linear format were tested; however, they did not yield reasonable or logical results. Several multiple linear regression forms were also tested and the most reasonable and logical one is presented in this article. The general form of the relationship, which describes ridership demand that was used in this research, is:

$$
\mathrm{Y}=\mathrm{a}_{0}+\mathrm{a}_{1} \mathrm{X}_{1}+\mathrm{a}_{2} \mathrm{X}_{2}+\ldots+\mathrm{a}_{\mathrm{r}} \mathrm{X}_{\mathrm{r}}
$$

Correlations between the independent variables were examined. Independent variables that had high correlation were either eliminated or joined as one variable. 


\section{Data Collection}

This research focused on the intercity bus services in the northern and central governorates of the West Bank, and considered the Nablus governorate as a core of this study. All city pairs with bus services in these areas were included. These cities are Jenin, Nablus, Qalqilia, Ramallah, Salfit, and Tulkarm. The cities represented the core of commercial, educational, and institutional activities in their respective governorates. Data was obtained from various sources, including:

- The Palestinian Central Bureau of Statistics (PCBS). The PCBS published the 1997 census, which described the population demographics and their activities in Gaza Strip and the West Bank. The PCBS also published "Transportation and Communication Statistics in the Palestinian Territories," (1999); "Expenditure and Consumption Levels" (1999); Labor Force Survey: Main Finding (2000); and Population, Housing and Establishment Census-1997, Final Results-West Bank (1999). This research considered the year 2000 as the base year. Thus, all the collected data were based on year 2000. External variables, which were examined in the ridership demand analysis, were obtained from the above PCBS publications. These were the total population by governorate, population economical activity, auto ownership, educational level, average monthly expenditure per family (Jordanian Dinar, JD), and auto ownership.

- Records of various public transportation agencies and bus companies. Data records of existing intercity bus trips were collected from bus company operators and transportation agencies. These data were weekly ridership, trip length (kilometer), travel time (minutes), bus fare (New Israeli Sheqel, NIS), and average number of bus trips.

- On-board survey (questionnaire). An on-board questionnaire was conducted to obtain riders' input regarding travel characteristics and profiles. Data obtained from this survey included rider's employment, income, auto ownership, educational attainment, trip purpose, number of similar weekly trips, and the main reason for riding the bus. 


\section{Data Analysis}

This section examines the characteristics of cities and intercity bus riders and presents the ridership model.

\section{Characteristics of Cities and Intercity Bus Riders}

The collected data for 22 city pairs indicated that Nablus and Ramallah had five bus service routes; Tulkarm, four; Jenin and Qalqilia, three; and Salfit, two.

\section{Table 1. Characteristics of Intercity Bus Services and Origin/Destination Citites}

Source: Several Palestinian Central Bureau of Statistics publications (1999) and bus companies.

\begin{tabular}{|c|c|c|c|c|c|c|c|c|}
\hline Origin & Popularloir & $\begin{array}{c}\% \\
\text { Studew }\end{array}$ & Destin. & $\begin{array}{c}\text { Wowly } \\
\text { Bus } \\
\text { Trips }\end{array}$ & $\begin{array}{c}\text { Trip } \\
\text { Length } \\
\text { in } \mathrm{K} / \mathrm{m}\end{array}$ & $\begin{array}{l}\text { Trawe } \\
\text { Time } \\
\text { in min }\end{array}$ & $\begin{array}{c}\text { Bus } \\
\text { Fare in } \\
\text { N/S }\end{array}$ & $\begin{array}{l}\text { Weckly } \\
\text { Ridership }\end{array}$ \\
\hline \multirow{5}{*}{ Nablus } & \multirow{5}{*}{278,300} & \multirow{5}{*}{34.9} & Ramalah & 209 & 53 & 35 & 6 & 6,500 \\
\hline & & & Jenin & 158 & $a$ & 30 & 5 & 7.614 \\
\hline & & & Tulkam & 179 & $y$ & 35 & 4 & 6,253 \\
\hline & & & QQzalçiliz & 72 & $\omega$ & $4 \mathrm{~s}$ & $s$ & 1,399 \\
\hline & & & Salfit & 42 & is & 40 & 3.5 & 1.005 \\
\hline \multirow{4}{*}{ Tuksm } & \multirow{4}{*}{142.909} & \multirow{4}{*}{363} & Nablus & 174 & 27 & 35 & 4 & 6263 \\
\hline & & & Jenin & 12 & 60 & 75 & G & 330 \\
\hline & & & Famallah & 18 & 50 & 80 & $y$ & 630 \\
\hline & & & Quluilis & $3 n$ & 50 & 60 & 5 & 480 \\
\hline \multirow{5}{*}{ Ramalah } & \multirow{5}{*}{231,700} & \multirow{5}{*}{$35 . n$} & Ratilus & 201 & 53 & 55 & S & $5,4 \infty$ \\
\hline & & & Jmin & 18 & ss & so & 10 & 220 \\
\hline & & & Tulkarm & 18 & 30 & 80 & 9 & 630 \\
\hline & & & Qualq̨ila & 78 & 64 & an & 7 & 425 \\
\hline & & & Sulfit & 9 & 30 & 50 & 5 & 240 \\
\hline \multirow{3}{*}{ Jenir } & \multirow{3}{*}{216.10} & \multirow{3}{*}{34.2} & riartislati & 18 & 85 & sn & 10 & 720 \\
\hline & & & Nablus & 196 & 42 & sII & 5 & 2,514 \\
\hline & & & Tulkarm & 12 & $\omega$ & is & 5 & 330 \\
\hline \multirow{3}{*}{ qalqlis } & \multirow{3}{*}{72,000} & \multirow{3}{*}{33.6} & Nablus & 72 & 40 & 45 & 5 & $3 . \times 0$ \\
\hline & & & Famullah & 78 & 68 & 8II & 7 & 495 \\
\hline & & & Tulkarm & 30 & $\leq 0$ & 60 & 6 & 699 \\
\hline \multirow{2}{*}{ Sefir } & \multirow{2}{*}{32,100} & \multirow{2}{*}{34.5} & Nablus & 42 & 35 & 40 & 35 & $1,+18$ \\
\hline & & & Ramallah & y & 90 & sa & 6 & 300 \\
\hline
\end{tabular}


Nablus City had the highest number of bus trips, as well as the highest number of riders. This can be attributed to the City's central location in the northern districts, existence of the largest university in the West Bank, and the fact that it is one of the largest commercial and business centers in the country. Table 1 shows that the highest average weekly bus trips were between Nablus and Ramallah cities (203 bus trips) and the least bus trips were between Ramallah and Salfit cities ( 9 bus trips).

Intercity bus ridership on a weekly basis was found to be the most reliable figure. The largest weekly ridership originated at Nablus City; the lea st ridership demand originated at Salfit City (see Table 1).

As shown in Table 1, the longest bus trip length (and travel time) was between Jenin and Ramallah ( 80 km, 90 minutes); the shortest bus trip length was between Nablus and Tulkarm (27 km, 35 minutes).

Bus fare is expected to be one of the most influential factors that affect ridership demand. As shown in Table 1, the highest bus fare was between Jenin and Ramallah (10.0 NIS); the lowest was between Nablus and Salfit (3.5 NIS).

Distribution of population by governorate showed that Nablus had the largest population $(278,300)$ while Salfit had the smallest population $(52,100)$, as shown in Table 2.

Table 2. Total Population and Percentage by Governorate

Source: Palestinian Central Bureau of Statistics. 2000. Palestine in the Twentieth Century-Statistical Stops.

\begin{tabular}{|l|c|c|}
\hline Governorate & Population & Percent \\
\hline Jenin & 216,100 & 6.9 \\
\hline Tulkarm & 142,900 & 4.5 \\
\hline Qalqilia & 78,000 & 2.5 \\
\hline Salfit & 52,100 & 1.7 \\
\hline Nablus & 278,300 & 8.8 \\
\hline Ramallah & 231,700 & 7.4 \\
\hline Palestinian Territories & $\mathbf{3 , 1 5 0 , 0 6 0}$ & $\mathbf{1 0 0 . 0}$ \\
\hline
\end{tabular}


Figure 2. Intercity Bus Rider's Trip Purpose

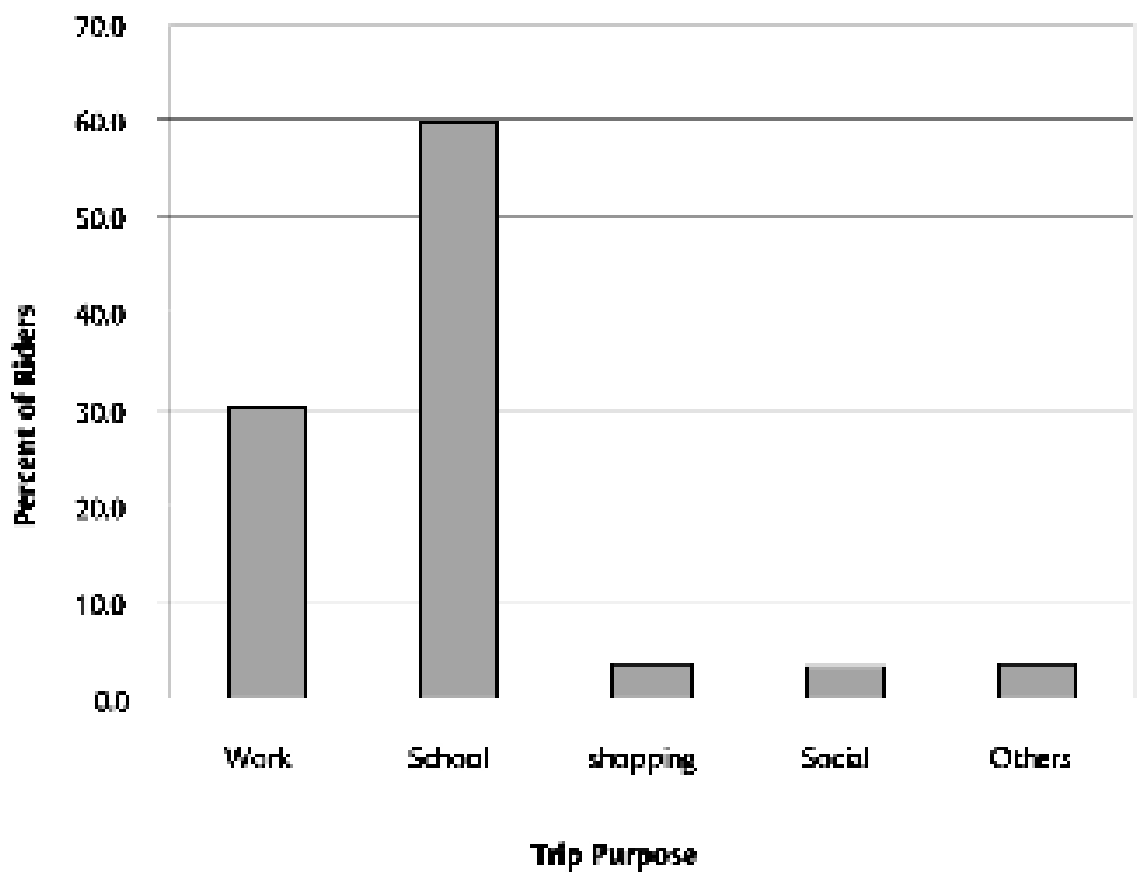

Figure 3. Percent Employment by Governorate

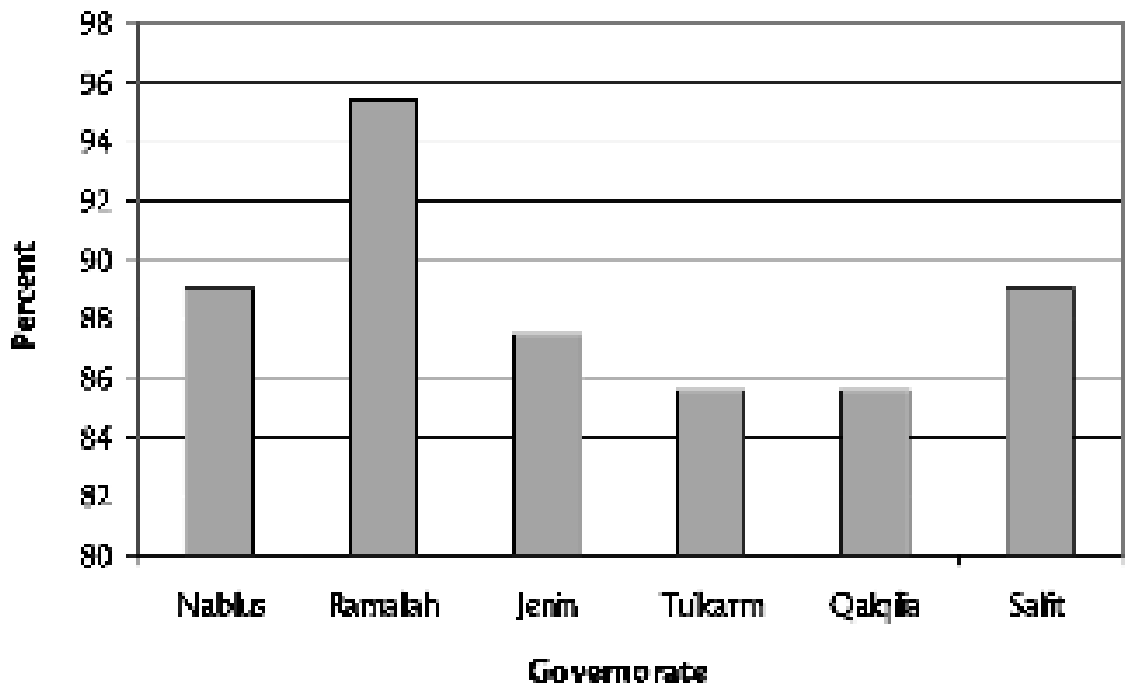


Based on the on-board survey, the most common trip purposes were educational, mostly for a university (59.8\%), and for work (30.7\%) as presented in Figure 2. Figure 3 shows that Ramallah had the largest employment percent (95.4\%) while Tulkarm and Qalqilia had the lowest employment percent (85.6\%).

Ramallah also had the highest average income/expenditure level expressed in terms of automobile ownership and family expenditure; Salfit had the lowest, as shown in Table 3.

Table 3. Average Family Expenditure and Automobile Ownership

\begin{tabular}{|l|c|c|}
\hline Governorate & $\begin{array}{c}\text { Average Family Monthly } \\
\text { Expenditure } \\
\text { (JD) }\end{array}$ & $\begin{array}{c}\text { No. of Private } \\
\text { Vehicles }^{2}\end{array}$ \\
\hline Jenin & 440 & 6190 \\
\hline Tulkarm & 443 & 7044 \\
\hline Qalqilia & 443 & 2336 \\
\hline Salfit & 464 & 2259 \\
\hline Nablus & 464 & 12028 \\
\hline Ramallah & 583 & 12715 \\
\hline Average/Total & $\mathbf{4 7 3}$ & $\mathbf{4 2 5 7 2}$ \\
\hline
\end{tabular}

1. Based on Expenditure and Consumption Levels, PCBS, 1999.

2. Based on Transportation and Communication Statistics in the Palestinian Territories, PCBS, 1999. 
Statistical analysis of the intercity bus service questionnaire showed that the highest two reasons that riders preferred using the bus service were the cost (45.9\%) and safety and comfort (29.0\%). Problems that riders faced while riding the bus included number of bus stops (29.8\%), waiting time (28.7\%), slo wness (14.2\%), walking distance to/from the bus station (9.7\%), discomfort (8.1\%), and other problems (9.6\%), as shown in Figure 4.

Figure 4. Bus Riders' Problems for Riding a Bus

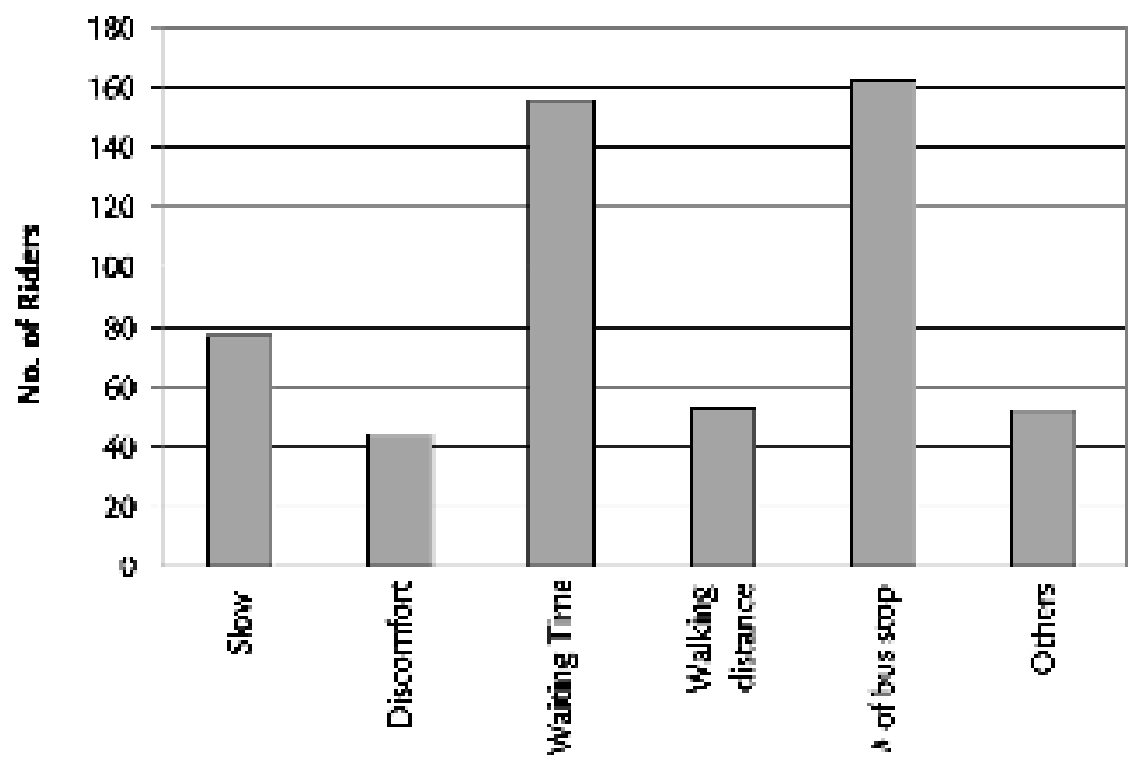

Type of Bus Problem

\section{Development of the Ridership Model}

The first step in developing the mathematical relationship was the establishment of a statistical correlation matrix among the different variables included in the study. The next step of regression modeling was to find the type of function between the dependent and independent variables such as linear or log linear functions. Trials and testing the types of functions in this study showed that the best relation between the dependent and the independent variables for the studied intercity public transport was the linear format. 
The selected independent variables were chosen based on their correlation and causation (logic). Initially, 14 independent variables were examined. Based on the set criteria, these variables were shorted to 5 :

- Origin city population in thousands, $\mathrm{D}_{1}$

- Destination city population in thousands, $\mathrm{D}_{2}$

- Bus fare in (NIS), D3

- Origin city percentage of students who are attending secondary schools or universities, D4

- Origin city percentage of people older than 15 years who are employed, $\mathrm{D}_{5}$ Using the multiple linear regression analysis, the following relationship was obtained:

$$
\mathrm{Y}=1084.8+26.8 \mathrm{D}_{1}+25.7 \mathrm{D}_{2}-813 \mathrm{D}_{3}+80.3 \mathrm{D}_{4}+68.3 \mathrm{D}_{5}
$$

The correlation coefficient, $\mathrm{R}^{2}$, for the above equation was 0.82 . The $t$-test and significance level statistics indicated that the variables had a good significance. Table 4 shows the values of the independent variables and the comparison between the observed and the predicted ridership demand using the above model.

The expected ridership demand for most city pairs was generally accepted, except those routes from or to Tulkarm and Salfit. Ridership from/to Tulkarm (except Tulkarm-Jenin) was underestimated. However, the overestimated ridership between Salfit and Nablus might be explained by the fact that Salfit is the smallest governorate in terms of population. Furthermore, the difference between bus fare and shared taxi fare for Nablus-Salfit trips (3.5 and 4.5 NIS, respectively) was marginal. Therefore, the incentive to use buses is low compared to other trip routes. Furthermore, the employment percentage for this governorate, reported in PCBS publications, was considered to be the same as employment for Nablus the governorate. This is obviously an overestimation for Salfit's employment level. 


\section{Table 4. Summary of Observed and Estimated Weekly Ridership Demand}

\begin{tabular}{|c|c|c|c|c|}
\hline Originfory & $\begin{array}{c}\text { Destimhar: } \\
\text { ray }\end{array}$ & $r_{2}$ & $r_{r}$ & $\begin{array}{l}\text { Percenit } \\
\text { Dijperence }\end{array}$ \\
\hline \multirow{5}{*}{ Nablus } & Raırallat & ssoo & 5867 & -15.0 \\
\hline & Jenin & $7.6: 4$ & 6.605 & 10.6 \\
\hline & Talkatni & 5763 & 5450 & .12 .3 \\
\hline & Qahilia & $333 n$ & 3274 & -1.7 \\
\hline & sulfit & $1,6 n 8$ & 2.540 & 152.0 \\
\hline \multirow{4}{*}{ Tulkzmı } & Vitulus & 5763 & 5500 & -6.2 \\
\hline & kewin & 330 & 2.849 & 703.0 \\
\hline & Rairsllah & 630 & 109 & -3.0 \\
\hline & Qabailis & 460 & 61 & .47 .9 \\
\hline \multirow{5}{*}{ Famalah } & Vabilus & 5,600 & $5.85 n$ & 9.5 \\
\hline & |erial & 720 & 810 & 18.1 \\
\hline & Tulkarm & 630 & $\pi$ & -66.3 \\
\hline & Qakpilis & 125 & 561 & 59.8 \\
\hline & Salfit & $2 i 0$ & 72 & 31.7 \\
\hline \multirow{3}{*}{ Jerin } & Rarrallah & $n 0$ & $\operatorname{sos}_{3}$ & 29.7 \\
\hline & vablus & $j, 614$ & 673 & $-12,0$ \\
\hline & Tulkarm & 130 & 2756 & 629.7 \\
\hline \multirow{3}{*}{ Qulqilia } & Nablus & 3,600 & 3,280 & $-11,8$ \\
\hline & Karrallah & 455 & Sed & -18.9 \\
\hline & Iularm & बev & 22 & -75.0 \\
\hline \multirow{2}{*}{ Salfir } & Noblus & 1,415 & 2,12 & 95.5 \\
\hline & Ramallah & 300 & 29 & -32.7 \\
\hline
\end{tabular}

$Y_{0}=$ Observed Weekly Ridership Demand

$\mathrm{Y}_{\mathrm{p}}=$ Predicted Weekly Ridership Demand

Percent Difference $=($ Predicted demand - Observed demand $) /$ Obs erved demand 


\section{Conclusions and Recommendations}

While bus ridership demand modeling has been well established in many developed countries, such efforts are nonexistent in the West Bank. Therefore, this is the first effort in analyzing existing intercity bus services and predicting future demand.

Based on the results of an intercity bus ridership analysis, ridership demand was derived from socioeconomic data and internal intercity service data using the multiple linear regression analysis.

A survey of riders, such as an on-board survey, is helpful in identifying primary variables influencing ridership. The factors that most influence intercity ridership for the study routes were origin and destination city population, percent of employees and students, and bus fare.

Riders reported that the number one reason for riding a bus was cost and the highest two problems with riding a bus were its high number of stops and waiting times. Furthermore, the overwhelming majority of trip purposes was educational and work.

It is natural that population and, thus trips, will increase in the future. Therefore, the transportation planning process should focus serious efforts on directing trips to public transportation.

This type of research cannot be feasible nor worthy as itself without the coordination with relevant authorities and decision-makers in considering the results and recommendations of this research.

Bus companies should explore providing express intercity bus service during peak periods to attract more riders such as students and employees who would like to arrive at work or classes on time.

Transportation planners and bus companies should investigate employing pricing policies to increase public transportation riders, especially daily commuters by offering weekly, monthly, or seasonal fare cards or special fares for specific groups such as students. The economic feasibility for the pervious recommendations should be investigated.

Furthermore, this study was conducted with limited data and financial resources. For similar future studies, it is recommended that databases with more detailed information about trips involving other transportation modes (shared taxi and private cars) be included. It is also recommended that future research include the Gaza Strip and southern districts of West Bank. 


\section{References}

Al-Sahili, K., and W. C. Taylor. 1996. Michigan intercity bus ridership study. Michigan State University.

Bermello, Ajamil, and Partners. 1997. Tri-Rail ridership demand forecasting. Draft Report. Miami.

Moussavi, M., M. Al-Turk, and J. Albeck. 1996. Non-urbanized public transportation needs assessment. Journal of Transportation Engineering 122 (6): 447-53.

Palestinian Central Bureau of Statistics. 1999. Expenditure and consumption levels. Final Report. Ramallah.

Palestinian Central Bureau of Statistics. 2000. Palestine in the Twentieth CenturyStatistical Stops. Ramallah.

Palestinian Central Bureau of Statistics. 1999. Population, Housing and Establishment Census - 1997, Final Results-West Bank. Ramallah.

Palestinian Central Bureau of Statistics. 1999. Transportation and communication statistics in the Palestinian territories. Annual Report. Ramallah.

Palestinian Central Bureau of Statistics. 2000. Labor Force Survey: Main Finding. Ramallah.

Wilbur Smith Associates. 2000. Traffic systems management studies for Jenin, Qalqilia, and Tulkarm Cities. Ramallah: Palestinian Economic Council for Development and Reconstruction.

\section{About the Authors}

Khaled A. Al-Sahil (alsahili@yahoo.com) holds B.S. and M.S. degrees in civil engineering from Jordan University of Science and Technology, and a Ph.D. in civil engineering from Michigan State University. He is currently the director of Construction and Transportation Research Center and an assistant professor in the civil engineering department at An-Najah National University in Nablus.

Mr. Al-Sahili's interest in transportation engineering includes traffic operations, traffic safety, and transportation planning. He has several years of academic and professional experience in the field of transportation engineering. 
Abdelmajid H. Sadeq holds B.S. and M.S. degrees of civil engineering from AnNajah National University, Palestine. He has several years of practical experience in the area of transportation and construction engineering. He is currently a city engineer in Gaza. 